\title{
INFLUÊNCIA DO PH DO MEIO DE CULTIVO E DA TURFA NO COMPORTAMENTO DE ESTIRPES DE Bradyrhizobium ${ }^{(1)}$
}

\author{
D. L. MIGUEL ${ }^{(2)} \&$ F. M. S. MOREIRA ${ }^{(3)}$
}

\begin{abstract}
RESUMO
A acidez dos solos representa um problema que afeta grandes áreas agrícolas pelo mundo, principalmente nos trópicos, onde fósforo e nitrogênio também são limitantes. No caso do nitrogênio, a fixação biológica torna-se uma das alternativas mais viáveis do ponto de vista ecológico e econômico, por di mi nuir o uso e o impacto causado pel os fertilizantes nitrogenados. Neste trabalho, foram realizados dois experimentos in vitro e um em casa de vegetação com quatro estirpes de Bradyrhizobium (Br 4406, Br 29, SE MIA 587 e INPA 03-11B), no Departamento de Ciência do Solo (UFLA), de julho de 1998 a jul ho de 1999, para verificar o efeito de três valores de pH $(5,0 ; 6,0 ; 6,9)$ no crescimento destas em meio de cultura YM, na sua si mbiose com soja, assi m como na sua sobrevivência em inoculantes produzidos com turfa. No primeiro experimento, as estirpes de Bradyrhizobium tiveram um comportamento diferenciado em meio líquido, obtendo melhor desempenho em pH 6,0, tanto em número de uni dades formadoras de colônias quanto em produção de exopolissacarídeos. +No segundo experimento, o número de nódulos, a atividade da nitrogenase (Nase), as massas secas de nódulos, raízes e parte aérea de plantas de soja, de modo geral, não foram influenciados pelos valores de pH de cultivo das estirpes no inoculante. Entretanto, a estirpe INPA 03-11B mostrou-se efetiva, apresentando número de nódulos e atividade de Nase semelhantes aos de Br 29 e SE MIA 587, que são recomendadas como estirpes inoculantes, devendo, assim, ser indicada para testes de eficiência em campo. No terceiro experimento, com exceção da $\mathrm{Br} 29$, que atingi u maior sobrevivência de células em pH 6,0, as outras estirpes tiveram sobrevivência semelhante neste valor de pH e em pH 6,9. O melhor desempenho das estirpes de Bradyrhizobium em pH 6,0 no meio de cultura e em turfa demonstrou a possibilidade do uso de inoculantes corrigidos para esse valor de pH, como modo de pré-adaptação às condições de acidez dos solos tropicais.
\end{abstract}

Termos de indexação: fixação biológica do $\mathrm{N}_{2}$, soja, inoculante turfoso, tolerância à acidez, produção de exopolissacarídeos.

(1) Parte da Tese de Mestrado em Solos e Nutrição de Plantas do primeiro autor, apresentada à Universidade Federal de Lavras UFLA. Recebido para publicação em setembro de 2000 e aprovado em junho de 2001.

(2) Pós-Graduando do Departamento de Ciência do Solo, Universidade Federal de Lavras - UFLA. Caixa Postal 37, CEP 37200-000 Lavras (MG). Bolsista da CAPES. E-mail: divino@cenargen.embrapa.br

(3) Professora Adjunta, Departamento de Ciência do Solo, UFLA. Bolsista do CNPq. E-mail: fmoreira@ufla.br 


\title{
SUMMARY: INFLUENCE OF MEDIUM AND PEAT PH ON THE BEHAVIOUR OF BRADYRHIZOBIUM STRAINS
}

\begin{abstract}
Soil acidity is one of the greatest problems faced in the management of agricultural lands around the world, mainly in the tropics, where phosphorus and nitrogen are also limiting factors. In the case of nitrogen, bi ol ogical nitrogen fixation is the most economical and ecological alternative to decrease the use and impact caused by nitrogen fertilizers. Two "in vitro" experiments and oneunder greenhouseconditions using four Bradyrhizobium strains (BR 4406, BR 29, SEMI A 587 and INPA 03-11B) werecarried out at theSoil Science Department, at Federal University of Lavras fromJ uly 1998 toJ uly 1999, aiming to verify the effect of three pH values (5.0; 6.0 and 6.9) on growth of Bradyrhizobium strains in YM medium, soybean symbiosis and peat survival. In the first experiment, Bradyrhizobium strains had diffentiated behaviour at the thre $\mathrm{pHs}$ of $\mathrm{YM}$ medium, and had the highest colony forming unities and exopolysaccharide production at $\mathrm{pH} 6.0$. In the second experiment, nodulenumber (NN), nitrogenase (Nase) activity, dry matter of nodules (NDM), roots (RDM) and shoots (SDM) of soybean were not affected by the different pHs of the culture medium used to produce peat inoculants. INPA 03-11B had similar efficiency to BR 29 and SEMIA 587, recommended as inoculant strains for soybean, on the production of NN, Nase activity, NDM, RDM and SDM. In the third experiment, all strains had the samecell survival at pH 6 and 6.9, except BR 29, which had thehighest survival at pH 6.0. The best behaviour of Bradyrhizobium strains at pH 6.0 in culture medium and in peat survival indicated the possibility to use this $\mathrm{pH}$ in the peat inoculant production as a means of acid adaptation to this soil stress condition in the tropics.
\end{abstract}

Index terms: Biological nitrogen fixation, soybean, peat based inoculant, acid tolerance, exopolysaccharide production.

\section{NTRODUÇÃO}

A acidez dos solos representa um problema que afeta grandes áreas agrícolas pelo mundo, principalmentenos trópicos, onde os teores defósforo e nitrogênio são limitantes. No caso do nitrogênio, a fixação biológica de nitrogênio (FBN) realizada pela simbiose de rizóbio com leguminosas, como a soja, pode suprir as necessidades de nitrogênio dessa cultura, quando a nodulação por estirpes eficientes é estabelecida. Portanto, a inoculação de estirpes sel ecionadas e de comprovada eficiência é uma das alternativas mais viáveis, ecológica eeconomicamente, podendo al cançar produções equivalentes às obtidas com fertilizantes nitrogenados, além de diminuir o uso e o impacto causado por eles (Dobereiner \& Duque, 1980).

A acidez dada pela concentração do íon $\mathrm{H}^{+}$(acidez ativa) e expressa na escala de pH está, normalmente, associada a outros fatores, como: saturação e toxidez por alumínioemanganês, baixa CTC edisponibilidade de nutrientes. Condições de acidez no solo atuam negativamentenas atividades da mi crobi ota do solo, principalmente dos microrganismos benéficos ao desenvolvimento e, ou, produção das plantas como os rizóbios, limitando sua multiplicação e sobrevivência, conseqüentemente reduzindo a nodulação e fixação de nitrogênio (Graham et al., 1982; Hartel \& Alexander, 1983; Graham, 1991).
Quando microrganismos crescem em condições levementeácidas (pH 5,6a 5,8), sendo posteriormente expostos a valores baixos de pH $(3,5$ a 4,0), sua sobrevivência à nova condição é significativamente maior do que se fossem previamente crescidos em condições ótimas ( $\mathrm{pH} 7,0)$. Esse fenômeno é denominado de "acid habituation" (Goodson \& Rowbury, 1989a,b) ou adaptativetol erance response (ATR) (O'Hara et al., 1989; Dilworth et al., 1999). Assim como em bactérias entéricas (Foster \& Hall, 1991; Fabber \& Pagatto, 1992), em rizóbio ATR envol ve a síntese de várias proteínas resultantes do choque provocado pela acidez (O'Hara \& Glenn, 1994), as quais auxiliam a membrana externa na recuperação dos fosfolipídeos, evitando os efeitos danosos da acidez (Correa \& Barnex, 1997). Diferenças na capacidade de crescimento em meios de cultura modificados com o intuito de simular os estresses associados à mai or concentração do íon $\mathrm{H}^{+}$ sobre a tol erância à aci dez de estirpes de rizóbio são citadas em vários trabal hos (Cunningham \& M unns, 1984a,b; Richardson \& Simpson, 1989; O'Hara \& Glenn, 1994; Reeveet al ., 1997; Dilworth et al ., 1999).

A sel eção de estirpes com mel hor crescimento em meio de cultura com valores de $\mathrm{pH}$ abaixo de 6,8 pode implicar melhor estabelecimento de sua simbiose nas condições de acidez predominante nos solos ácidos tropicais (Howieson \& Ewing, 1986). Além disso, condições de acidez no meio de cultivo e 
nos inoculantes podem favorecer a pré-adaptação à acidez dos solos.

Sendo assim, este trabalho teve por objetivo verificar se o pH do meio de cultivo das estirpes edo inoculante turfoso pode favorecer o crescimento, a sobrevivência ea eficiência da sua simbiose com soja.

\section{MATERIAL E MÉTODOS}

O estudo constou de dois experimentos in vitro e um em casa de vegetação e foi desenvolvido no Departamento de Ciência do Solo na U niversidade Federal de Lavras - UFLA, Lavras (MG), dejulho de 1998 a julho de 1999.

\section{Estirpes estudadas}

Foramestudadas quatroestirpes deBradyrhizobium: duas estirpes de B. elkani i (SEMIA 587 e Br $29=$ SEM I A 5019), lançadas como estir pes inoculanteem 1968 e 1979, respectivamente, que são eficientes na simbiose com Glycine max (soja) e consideradas competitivas em solos de Cerrado (Peres \& Vidor, 1980). A estirpe Br 4406, classificada como B. japonicum (Moreira et al., 1998), microssimbionte de Enterolobium contortisilyquum. (Vell) Morong (tamboril), vem-se destacando principalmente, pela tolerância à acidez (RibeiroJ r. et al., 1986) ea metais pesados (Matsuda, 2000; Trannin et al., 2001). A estirpe INPA 03-11B, isolada de Centrosema sp em solos de terra firme da Amazônia, é eficiente em Vigna ungui culata (feijão caupi) (Magalhães, 1986) e, atéo momento, não tem definição quanto à espécie.

\section{Experimento I}

Para avaliar o comportamento das estirpes em meio líquido com diferentes val ores de pH, colônias isoladas de cada estirpe foram obtidas em meioYMA (yeast mannitol agar) (Vincent, 1970) e inoculadas em erlenmeyer que continha $250 \mathrm{~mL}$ de meio YM (yeast mannitol) com pH 5,0; 6,0 e 6,9 ajustado com solução de $\mathrm{HCl} 2 \mathrm{~mol} \mathrm{~L}^{-1}$ e crescidas sob agitação orbital a $110 \mathrm{rpm}$ a $28^{\circ} \mathrm{C}$. A partir de $48 \mathrm{~h}$ de crescimento ea cada $24 \mathrm{~h}$, foram retiradas alíquotas de $5 \mathrm{~mL}$ de cada cultura para determinação da densidade ótica a $560 \mathrm{~nm}$ em um espectrofotômetro B 395 (Micronal) e contagem do número de unidade formadoras de colônias (UFC) (Miles \& Misra, 1938) pelo método de diluições sucessivas em solução salina ( $\mathrm{NaCl} 0,55 \%)$ e inoculação em placas com YMA.

O número de UFC foi calculado por contagem direta do número de colônias nas placas em cada diluição, sendo obtidas equações de regressão pela relação do logaritmo do número deUFC por mililitro de meio de cultura de acordo com o tempo e densidade ótica. Assim, pela densidade ótica das culturas, pode-se comparar a produção de polissacarídeos entre as estirpes, tomando-se o número base de $10^{8,8} \mathrm{UFC} \mathrm{mL}^{-1}$ para todas as estirpes. Esse número foi determinado na fase log, na tentativa de obter somente células viáveis, diminuindo, assim, a interferência da faseestacionária (morte celular) nas leituras de densidade ótica.

\section{Experimento II}

Este experimento teve por objetivo estudar o efeito de inoculantes, produzidos com estirpes de Bradyrhizobium crescidas em diferentes val ores de $\mathrm{pH}$, na nodulação e no cresci mento de plantas de soja da variedade CAC-1, cultivadas em casa de vegetação. O experimento constou de um delineamento inteiramente casualizado com quatro estirpes etrês valores de pH $(5,0 ; 6,0$ e 6,9) com cinco repetições, além de um tratamento-testemunha com nitrogênio e outro sem nitrogênio, sendo ambos sem inoculação. Para o tratamento com nitrogênio, foi utilizado $\mathrm{NH}_{4} \mathrm{NO}_{3}$ como fonte de $\mathrm{N}$, sendo aplicados $50 \mathrm{mg} \mathrm{dm}^{-3}$ de $\mathrm{N}$ no solo na semeadura e $150 \mathrm{mg} \mathrm{dm}^{-3}$ de $\mathrm{N}$ no solo 15 dias após.

Na produção dos inoculantes, curvas de regressão obtidas no primeiro experimento foram utilizadas para padronizar $10^{9}$ células $\mathrm{mL}^{-1}$ de meio que foram misturados à turfa $(50 \mathrm{~mL}$ demeio de cultura: $150 \mathrm{~g}$ de turfa). Os inoculantes foram aplicados às sementes na base de $500 \mathrm{~g}$ para 50.000 sementes. Foram plantadas duas sementes por vaso com desbaste posterior para uma planta por vaso.

Utilizou-se Latossolo Vermel ho-Amarelo (LA) textura argil osa fase cerrado, col etado no município de Lavras (MG), na camada de $0-20 \mathrm{~cm}$ de profundidade, seco ao ar e peneirado em malha de $5,0 \mathrm{~mm}$. Os resultados das análises químicas e físicas, seguindo método proposto por Vettori (1969) e modificado pela EMBRAPA (1979) e Camargo et al. (1986), encontram-se no quadro 1.

Para suprir a necessidade de calagem, foi adicionado cal cário dol omítico, objetivando el evar o índice de saturação por bases (V) para $60 \%$. O solo foi incubado por 15 dias, com teor de água em torno de $70 \%$ do volume total de poros (VTP). Passado o período de incubação, o solo foi seco ao ar e acondicionado em vasos de tubo de PVC com capacidade de 1,4 dm 3 . Para suprir a deficiência em nutrientes minerais, uma solução nutritiva foi adicionada, constituída de $200 \mathrm{mg} \mathrm{kg}^{-1}$ de $\mathrm{P}$ $\left(\mathrm{KH}_{2} \mathrm{PO}_{4}\right) ; 300 \mathrm{mg} \mathrm{kg}^{-1}$ de $\mathrm{K}\left(\mathrm{K}_{2} \mathrm{SO}_{4}\right) ; 30 \mathrm{mg} \mathrm{kg}^{-1} \mathrm{de}$ $\mathrm{Mg}\left(\mathrm{MgSO}_{4}\right.$. $\left.7 \mathrm{H}_{2} \mathrm{O}\right) ; 0,5 \mathrm{mg} \mathrm{kg}^{-1}$ de $\mathrm{B}\left(\mathrm{H}_{3} \mathrm{BO}_{3}\right)$; $1,5 \mathrm{mg} \mathrm{kg}^{-1}$ de Cu $\left(\mathrm{CuSO}_{4} \cdot 5 \mathrm{H}_{2} \mathrm{O}\right) ; 0,1 \mathrm{mg} \mathrm{kg}^{-1}$ deMo $\left(\left(\mathrm{NH}_{4}\right)_{6} \mathrm{MoO}_{24} \cdot 4 \mathrm{H}_{2} \mathrm{O}\right) ; 5 \mathrm{mg} \mathrm{kg}^{-1}$ de $\mathrm{Zn}\left(\mathrm{ZnSO}_{4} \cdot 7 \mathrm{H}_{2} \mathrm{O}\right)$ e $50 \mathrm{mg} \mathrm{kg}^{-1}$ de S (contido nas fórmulas anteriores). O potássio foi parcelado em três aplicações iguais, uma no plantio e as outras aos 20 e 35 dias da emergência das plântulas.

As plantas foram col hidas durante o período da floração, 55 dias após semeadura, sendo a parte aérea cortada na al tura do col o. O sistema radicular 
Quadro 1. Características químicas e físicas do solo utilizado

\begin{tabular}{|c|c|}
\hline Característica & Valor \\
\hline pH, em água & 5,5 \\
\hline Alumínio, $\mathrm{cmol}_{\mathrm{c}} \mathrm{dm}^{-3}$ & 0,0 \\
\hline Fósforo, $\mathrm{mg} \mathrm{dm}^{-3}$ & 1,0 \\
\hline Potássio, $\mathrm{mg} \mathrm{dm}^{-3}$ & 75 \\
\hline Cálcio, $\mathrm{cmol}_{\mathrm{c}} \mathrm{dm}^{-3}$ & 1,1 \\
\hline Magnésio, $\mathrm{cmol}_{\mathrm{c}} \mathrm{dm}^{-3}$ & 0,6 \\
\hline Ac. potencial, $\mathrm{cmol}_{\mathrm{c}} \mathrm{dm}^{-3}$ & 4,0 \\
\hline Soma de bases, $\mathrm{cmol}_{\mathrm{c}} \mathrm{dm}^{-3}$ & 1,9 \\
\hline CTC efetiva, $\mathrm{cmol}_{\mathrm{c}} \mathrm{dm}^{-3}$ & 1,9 \\
\hline СТC a pH 7,0, $\mathrm{cmol}_{\mathrm{c}} \mathrm{dm}^{-3}$ & 5,9 \\
\hline Sat. bases, \% & 32,2 \\
\hline Sat. alumínio, \% & 0,0 \\
\hline Ferro, $\mathrm{mg} \mathrm{dm}^{-3}$ & 156,2 \\
\hline Zinco, $\mathrm{mg} \mathrm{dm}^{-3}$ & 5,4 \\
\hline Cobre, $\mathrm{mg} \mathrm{dm}{ }^{3}$ & 4,1 \\
\hline Matéria orgânica, dag kg-1 & 3,71 \\
\hline Carbono, dag kg-1 & 2,15 \\
\hline Areia, $\mathrm{g} \mathrm{kg}^{-1}$ & 560 \\
\hline Argila, $\mathrm{g} \mathrm{kg}^{-1}$ & 190 \\
\hline Silte, $\mathrm{g} \mathrm{kg}^{-1}$ & 250 \\
\hline
\end{tabular}

Extratores: $\mathrm{Ca}, \mathrm{Mg}$ e $\mathrm{Al}=\mathrm{KCl} 1 \mathrm{~mol} \mathrm{~L}^{-1}$; $\mathrm{P}$ e $\mathrm{K}=$ Mehlich-1; $(\mathrm{H}+\mathrm{Al})=$ acetato de cálcio $0,5 \mathrm{~mol} \mathrm{~L}^{-1}$ a pH 7,0; $\mathrm{Mn}, \mathrm{Fe}, \mathrm{Zn}$ e $\mathrm{Cu}=\mathrm{DTPA}$.

e os nódulos foram retirados cuidadosamente (evitando-se destacamento dos nódulos das raízes) do torrão formado para medir a atividade da enzima nitrogenase pelo método de redução de acetileno (Dilworth, 1966) em raízes intactas. Para isso, após lavagem, as raízes foram colocadas em frascos de $500 \mathrm{~mL}$ com tampa rosqueada e rol ha de borracha, por onde foram retirados $10 \%$ do volume em ar da atmosfera do frasco e injetado o mesmo volume de acetileno $\left(\mathrm{C}_{2} \mathrm{H}_{4}\right)$. Após incubação por duas horas, procedeu-se à injeção de $1 \mathrm{~mL}$ da amostra gasosa em um cromatógrafo a gás Variant 3400 CX. Então, os nódul os for am destacados manual mente do sistema radicular, contados e col ocados para secar em estufa com circulação de ar a 60-70C, para determinação da massa seca de nódulos, raízes e parte aérea.

\section{Experimento III}

Para avaliar o efeito do $\mathrm{pH}$ do inoculante, constituído do meio de cultivo e da turfa, na sobrevivência das estirpes, estas foram cultivadas em YM com pH ajustados para 6,0 e 6,9, até à obtenção de cerca de $10^{9}$ células $\mathrm{mL}^{-1}$ e misturadas à turfa corrigida para valores depH correspondentes.

A turfa utilizada foi cedida pel o Centro Nacional de Pesquisa emAgrobiologia (CNPAB) - EMBRAPA, local onde foi seca ao ar, passada em peneira de 200 mesh e analisada quimicamente (Quadro 2).
Quadro 2. Análise química da turfa

\begin{tabular}{lc}
\hline Característica & Valor \\
\hline Nitrogênio, \% & 0,57 \\
Carbono, \% & 16,04 \\
pH & 3,6 \\
Alumínio, $\mathrm{cmol}_{\mathrm{c}} \mathrm{dm}^{-3}$ & 0,3 \\
Cálcio, $\mathrm{cmol}_{\mathrm{c} \mathrm{dm}} \mathrm{dm}^{-3}$ & 8,0 \\
Magnésio, $\mathrm{cmol}_{\mathrm{c}} \mathrm{dm}^{-3}$ & 4,0 \\
Fósforo, $\mathrm{mg} \mathrm{dm}^{-3}$ & 89 \\
Potássio, $\mathrm{mg} \mathrm{dm}^{-3}$ & 610 \\
Sódio, $\mathrm{mg} \mathrm{dm}^{-3}$ & 68 \\
\hline
\end{tabular}

Para correção do pH da turfa, foi realizada uma curva de incubação com 1, 2, 3, 4, 5 e 6\% de carbonato de cálcio $\left(\mathrm{CaCO}_{3}\right)$. Assim, foram adicionados 3,0 e 4,3\% (v/v) de carbonato de cálcio para obtenção dos valores de pH 6,0 e 6,9, respectivamente.

Porções de $5 \mathrm{~g}$ de turfa com $\mathrm{pH}$ corrigido foram colocadas em sacos de polipropileno $(10 \times 15 \times$ $0,06 \mathrm{~cm}$ ), os quais foram lacrados em seladora a quente e autoclavados por duas vezes, durante uma hora a $121^{\circ} \mathrm{C}$ em interval os de $24 \mathrm{~h}$ (Sparrow \& Ham, 1983). Com o uso de seringas estéreis, $2 \mathrm{~mL}$ de cultura bacteriana com aproximadamente $10^{9}$ de células $\mathrm{mL}^{-1}$ de meio foram injetados nos sacos de polipropileno. O local da perfuração foi limpo com al godão estéril embebido em álcool etílico 70\% e coberto com fita adesiva esterilizada em autoclave. Manualmente, cada pacote (total $=30$ pacotes/ estirpes) foi agitado vigorosamente, para garantir a completa homogeneidade do inoculante, que foi, posteriormente, armazenado sob temperatura de 2830C (Figueiredo et al., 1991).

Foram realizadas as avaliações do número de unidades formadoras de colônias (UFC), aos 15, 30, 45, 60 e 75 dias da inoculação, em três repetições (três pacotes de inoculante) de cada estirpe. Para isso, $5 \mathrm{~g}$ do inoculante foram colocados em erlenmeyer que continha $95 \mathrm{~mL}$ de solução salina $(\mathrm{NaCl}$ 0,55\%) e agitados por um minuto, seguindose as diluições sucessivas em tubos com $9 \mathrm{~mL}$ da mesma solução(Vincent, 1970). Alíquotas de 0,02 mL a partir da diluição $10^{-4}$ até $10^{-9}$ foram inoculadas em placas com meio YMA e incubadas a $28^{\circ} \mathrm{C}$ durante sete dias.

Em todos os ensaios, após análise de variância, os dados for am comparados entre tratamentos pelo teste de Duncan $(p>0,05)$, empregando-seo Sistema de Análise Estatísticas e Genéticas (SAEG 5.0). O valor de $\mathrm{F}$ foi calculado e testado pelo programa F calc 32 versão 1.1 . 


\section{RESULTADOS E DISCUSSÃO}

\section{Comportamento das estirpes deBradyrhizobium spp crescidas em meio líquido com diferentes valores de $\mathrm{pH}$}

O comportamentodas estirpes de Bradyrhizobium foi diferenciado em cada $\mathrm{pH}$ de cultivo, tendo todas as estirpes crescido melhor em pH 6,0 (Figura 1), onde al cançaram os maiores números de unidades formadoras de colônias. Em pH 5,0, a estirpe INPA 03-11B apresentou um crescimento menor em relação a pH 6,0 e 6,9 até168 h. A partir destetempo, o crescimento foi semel hante, chegando a superar os demais val ores de $\mathrm{pH}$ testados. Esta diferença nas primeiras horas de crescimento pode ser devida à maior inibição do crescimento na fase log, proporcionada pela acidez mais el evada, indicando que a tolerância ao pH baixo é dependente da fase de crescimento (O'Hara \& Glenn, 1994; Correa \& Barnex, 1997). Keyser \& Munns, (1979a,b) e Thornton \& Davey (1983) também observaram um aumento da fase log em estirpes de Bradyrhizobi um em meio líquido quando crescidas em $\mathrm{pH} 4,5$. J á as estirpes Br 4406, Br 29 e SEMIA 587 tiveram comportamento semel hante em pH 5,0 e 6,9.

O tempo necessário para atingir crescimento máximo, obtido por meio das equações de regressões (Figura 1), também foi menor em pH 6,0, sendo de $146 \mathrm{~h}$ para $\mathrm{Br} 4406,143$ para $\mathrm{Br}$ 29, 155 para SEMIA 587 e 148 para INPA 03-11B (Quadro 3), indicando melhor adaptação das estirpes de Bradyrhizobium estudadas ao pH levemente ácido. Os números de UFC em pH 5,0, em geral, foram semel hantes em relação ao pH 6,9, porém o tempo necessário para crescimento máximo foi diferenciado, exceto para SEMIA 587.

A densidade ótica é resultante do número de células somado à produção de exopolissacarídeos. Tomando como base um mesmo número de UFC $\left(10^{8,8} \mathrm{UFC} \mathrm{mL}^{-1}\right)$ para todas as estirpes na fase log e fazendo uso das equações de regressão da figura 2 , foram obtidas densidades com diferenças relativas apenas à produção de polissacarídeos. A produção
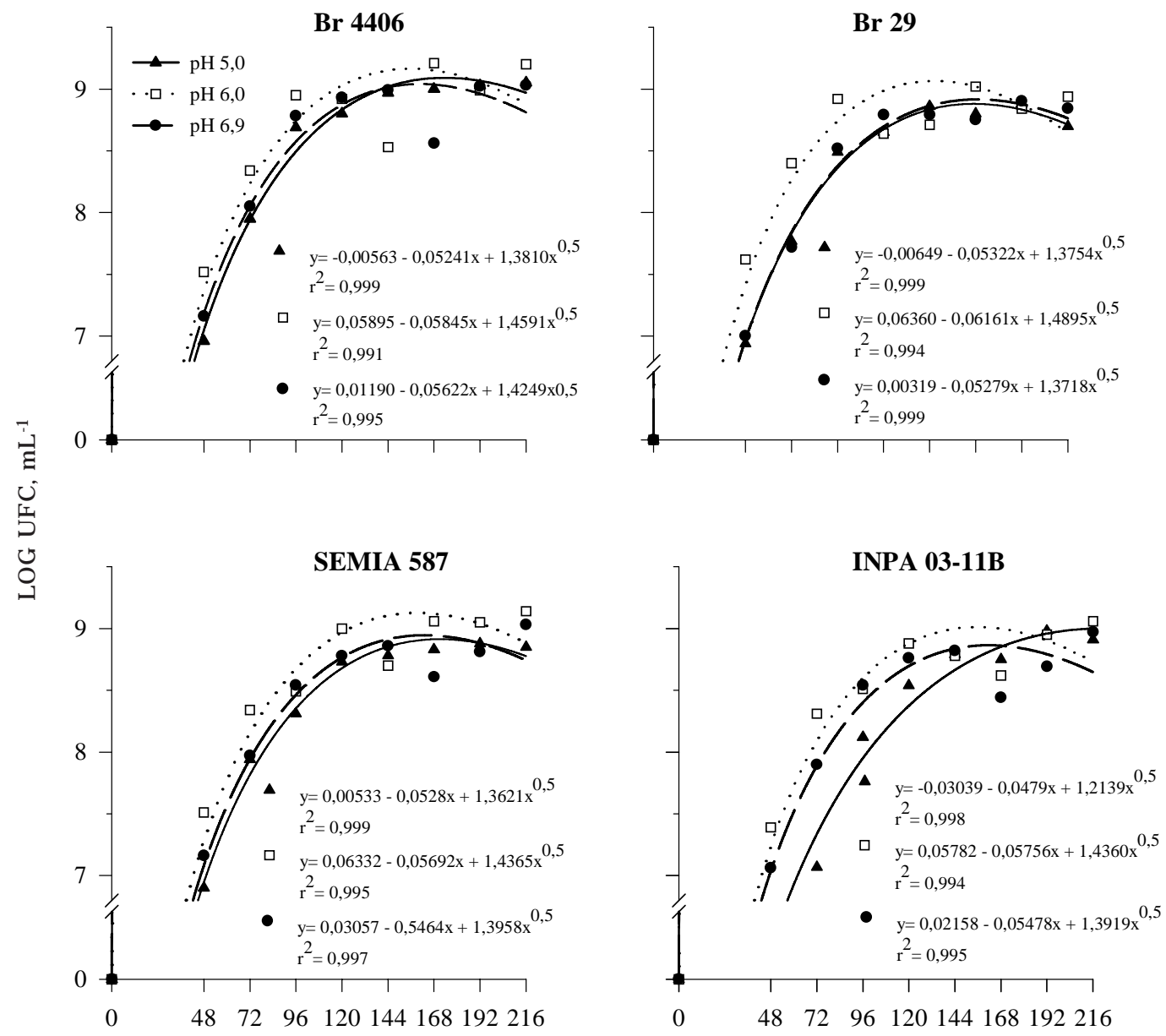

TEMPO, $h$

Figura 1. Comportamento de estirpes de Bradyrhizobi um em meio líquido, considerando o pH de cultivo. 
Quadro 3. Tempo necessário para o cresci mento máximo de quatro estirpes de Bradyrhizobi um em meio YM (Vincent, 1970) com diferentes valores de pH

\begin{tabular}{|c|c|c|c|c|c|c|c|c|}
\hline \multirow{3}{*}{ pH } & \multicolumn{8}{|c|}{ Estirpe } \\
\hline & \multicolumn{2}{|c|}{ Br 4406} & \multicolumn{2}{|c|}{ Br 29} & \multicolumn{2}{|c|}{ SE MIA 587} & \multicolumn{2}{|c|}{ INPA 03-11B } \\
\hline & Tempo (h) & UFC & Tempo (h) & UFC & Tempo (h) & UFC & Tempo (h) & UFC \\
\hline 5,0 & 165 & 9,09 & 159 & 8,88 & 161 & 8,91 & 210 & 9,00 \\
\hline 6,0 & 146 & 9,16 & 143 & 9,07 & 155 & 9,13 & 148 & 9,01 \\
\hline 6,9 & 154 & 9,04 & 165 & 8,92 & 161 & 8,95 & 152 & 8,86 \\
\hline
\end{tabular}

de exopolissacarídeos foi diferenciada entre as estirpes conforme o $\mathrm{pH}$ de cultivo, sendo as maiores quantidades obtidas em pH 6,0 (Figura 3). Em $\mathrm{pH}$ 5,0 e 6,9, a estirpe $\mathrm{Br} 4406$ que apresentou, de modo geral, maior número de UFC em relação às demais, também apresentou maior produção de exopolissacarídeos. Esses resultados estão em acordo com a proposta de Cunninghan \& Munns (1984a) de que a produção de polissacarídeos está associada à maior tolerância à acidez. Entretanto, de acordo com Neves et al. (1992), isolados de Br 33 (B. japonicum), após adaptação às condições de acidez em campo, diminuíram a quantidade de exopol issacarídeos. Segundo Graham et al. (1982), o acúmulo de exopolissacarídeos é o resultado da incompleta síntese da membrana externa. Assim, a produção de exopol issacarídeos é um investimento significativo em termos de gasto de energia sob condições de estresse de prótons, pois as células têm mais urgência no uso destes carboidratos em outras funções (Dilworth et al., 1999). Esses mesmos autores revelaram, ainda, que o fenômeno da "acid habituation", o qual envolve a síntese de várias proteínas, principalmente proteínas da membrana externa, e o controle do pH citoplasmático proporcionariam resistência à perda de nutrientes necessários à manutenção destes sistemas. Assim, num cultivo subseqüente, as células crescidas em pH abaixo de 7,0 poderiam produzir maior número de UFC do que as crescidas em pH 7,0.

Assim, os resultados deste experimento demonstraram um comportamento diferenciado das estirpes deBradyrhizobium em meio líquido em função do pH, tanto em número de UFC quanto em produção de exopolissacarídeos. O melhor desempenho em pH 6,0 apresentado pelas estirpes estudadas pode estar relacionado com uma resposta adaptativa ao meio levemente ácido promovido pela produção de exopolissacarídeos.

Resposta da soja a inoculantes produzi dos com
estirpes cultivadas em diferentes valores de pH

O número de nódulos (NN), atividade da nitrogenase (Nase) e massa seca de nódulos (MSN), raízes (MSR) e parte aérea (MSPA) de plantas de soja inoculadas com quatro estirpes de Bradyrhizobium crescidas em diferentes valores de $\mathrm{pH}$ e os tratamentos com e sem nitrogênio encontram-se no quadro 4.

A produção de MSPA eMSR, em geral, não diferiu entre as estirpes $\mathrm{Br} 29$, SEMIA 587 e INPA 03-11B em relação ao $\mathrm{pH}$ de cultivo das estirpes. As maiores produções de MSR ocorreram no tratamento com nitrogênio, não diferindo da estirpe SEMIA 587 cultivada no $\mathrm{pH} 6,9$, coincidindo com os maiores resultados para matéria seca da parte aérea nos mesmos tratamentos. As plantas inoculadas com a estirpe $\mathrm{Br} 4406$ tiveram as menores produções, evidenciando a ineficiência dessa estirpe na simbiose com soja.

Com exceção do NN da estirpe I NPA 03-11B, não houve influência do $\mathrm{pH}$ decultivo das estirpes sobre as variáveis MSN e NN, estando os valores das estirpes Br 29, SE MIA 587 eI NPA 03-11B deacordo com aqueles encontrados por Morote et al. (1990), Oliveira et al. (1991) ePeres et al. (1993), para estas variáveis. Segundo Vargas et al. (1982) e Vargas \& Suhet (1980), para uma simbiose eficiente, uma planta de soja na época de florescimento deve apresentar entre 15 e 30 nódul os ou de 100 a 200 mg de nódulos secos.

Os menores valores para NN e MSN foram observados nos tratamentos com a estirpe $\mathrm{Br} 4406$, recomendada como sendo de eficiência comprovada quando inoculada em Enterol obi um contortisi liquum (tamboril) (RibeiroJ r. et al., 1986) e capaz de crescer em meio de cultura com elevada acidez (RibeiroJ r. et al., 1987). O baixo número denódulos pode ser devido, provavelmente, à alta especificidade hospedeira apresentada pela soja. Alguns cultivares de soja apresentam grau considerável de especificidade quando inoculadas com determinadas estirpes de Bradyrhizobium japonicum (Vidor et al., 1983). A especificação hospedeira éa habilidade de uma estirpe de rizóbio em promover a nodulação em espécies, variedades e, ou, cultivares de determinada espécie deleguminosa. No caso da soja, existe certo grau de sel etividade (Peres \& Vidor, 1980; Vidor et al., 1983). 

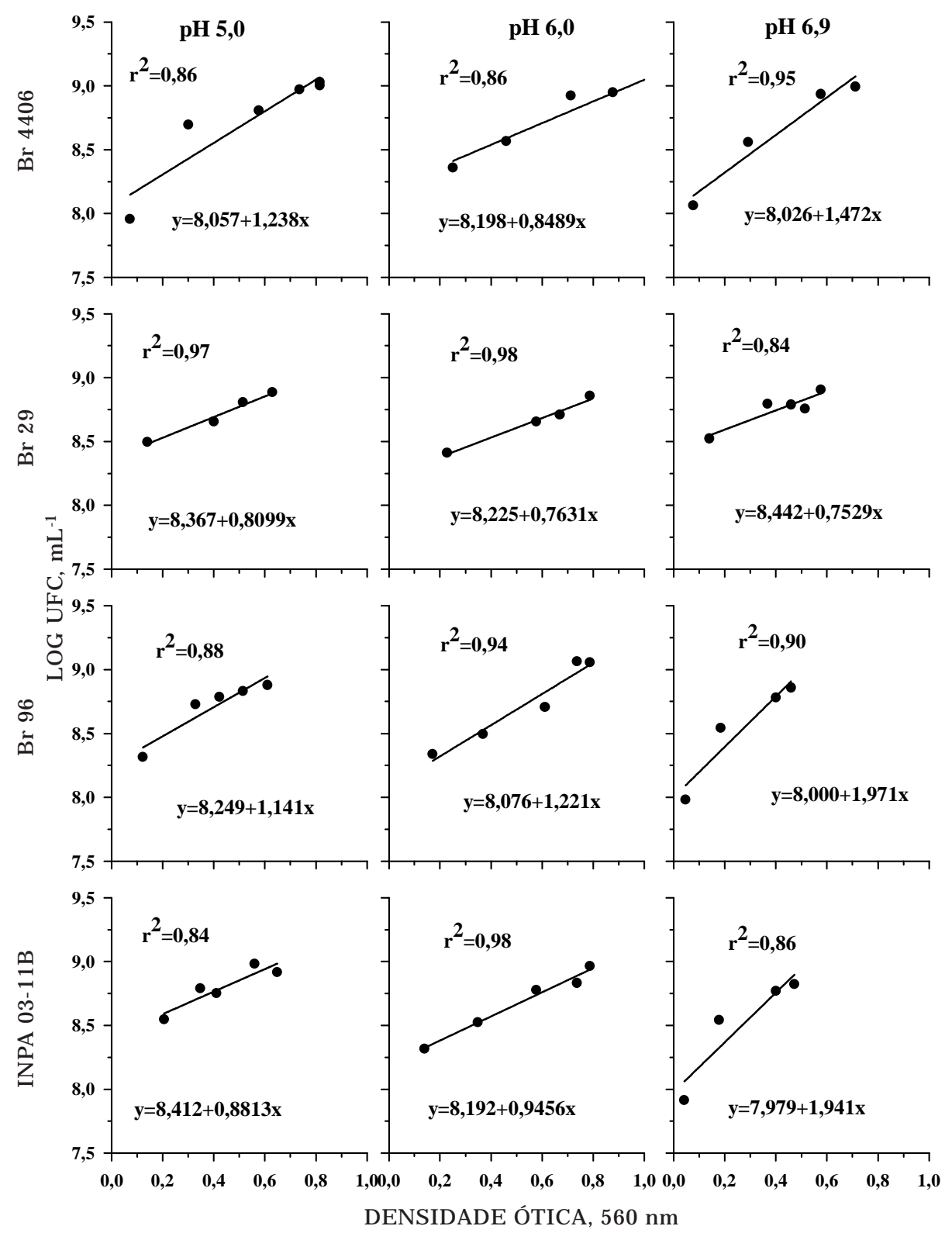

Figura 2. Relação entre o Log de UFC, considerando a densidade ótica das estirpes de Bradyrhizobium nos valores de pH 5,0; 6,0 e 6,9.

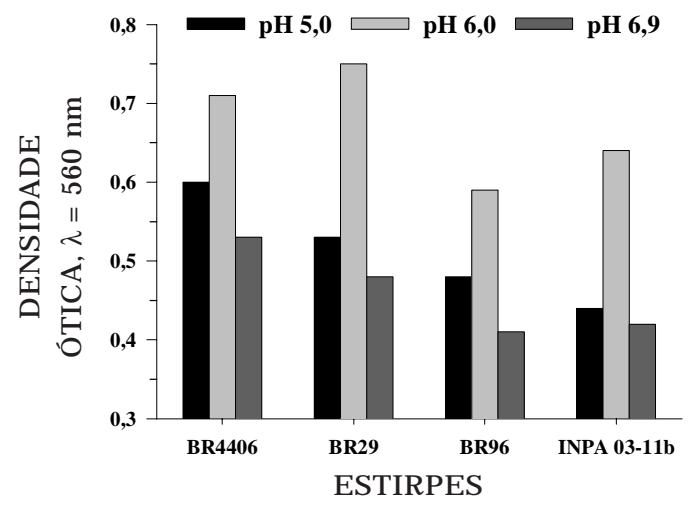

Figura 3. Densidade ótica de estirpes de Bradyrhizobi um em $10^{8,8} \mathrm{UFC} \mathrm{mL}^{-1}$, considerando o pH de cultivo. 
Quadro 4. Número de nódulos, atividade da nitrogenase, massa de nódulos secos, massa da parte aérea seca e massa de raízes secas de plantas de soja inoculadas com estirpes de Bradyrhizobium spp crescidas em YM com diferentes valores de pH e aplicadas às sementes via turfa, bem como plantas não inoculadas com e sem adubação com nitrogênio

\begin{tabular}{|c|c|c|c|c|c|c|}
\hline \multicolumn{2}{|c|}{ Tratamento } & \multirow{2}{*}{ Número nódulo } & \multirow{2}{*}{ Atividade/nitrogenase } & \multicolumn{3}{|c|}{ Massa seca } \\
\hline \multirow[t]{2}{*}{ Estirpe } & pH & & & Nódulo & Raiz & Parte aérea \\
\hline & & & $\mu \mathrm{mol} \mathrm{s} \mathrm{s}^{-1}$ planta- $^{-1}$ & $-\varsigma$ & 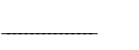 & \\
\hline \multirow[t]{3}{*}{$\mathrm{Br} 4406$} & 5,0 & $2 \mathrm{e}$ & $83 \mathrm{~cd}$ & $0,01 \mathrm{c}$ & $1,64 d$ & $3,2 \mathrm{e}$ \\
\hline & 6,0 & $1 \mathrm{e}$ & $12 \mathrm{~d}$ & $0,00 \mathrm{c}$ & $1,63 \mathrm{~d}$ & $2.9 \mathrm{e}$ \\
\hline & 6,9 & $1 \mathrm{e}$ & $43 \mathrm{~cd}$ & $0,01 \mathrm{c}$ & $1,72 \mathrm{~d}$ & 3.4 de \\
\hline \multirow[t]{3}{*}{ Br29 } & 5,0 & $55 \mathrm{abc}$ & $1.663 \mathrm{a}$ & $0,16 \mathrm{~b}$ & $1,63 \mathrm{~d}$ & $4.1 \mathrm{bc}$ \\
\hline & 6,0 & $62 a$ & $2.114 \mathrm{a}$ & $0,19 a b$ & $1,85 \mathrm{~cd}$ & $4.4 \mathrm{bc}$ \\
\hline & 6,9 & $57 a b$ & $2.437 \mathrm{a}$ & $0,19 a b$ & $1,84 \mathrm{~cd}$ & $4.7 \mathrm{ab}$ \\
\hline \multirow[t]{3}{*}{ SEMIA 587} & 5,0 & $43 \mathrm{~cd}$ & $223 b c$ & $0,18 a b$ & $1,81 \mathrm{~cd}$ & $4,3 \mathrm{bc}$ \\
\hline & 6,0 & $49 a b c$ & $220 \mathrm{bc}$ & $0,19 a b$ & $1,83 \mathrm{~cd}$ & $4,5 a b$ \\
\hline & 6,9 & $48 a b c$ & $657 \mathrm{~b}$ & $0,24 a$ & $2,24 \mathrm{ab}$ & $5,1 \mathrm{a}$ \\
\hline \multirow[t]{5}{*}{ INPA 03-11B } & 5,0 & $44 \mathrm{bcd}$ & $1.662 \mathrm{a}$ & $0,18 a b$ & $1,84 \mathrm{~cd}$ & $4,6 a b$ \\
\hline & 6,0 & $36 \mathrm{~d}$ & $1.566 \mathrm{a}$ & $0,24 \mathrm{a}$ & 2,16 abc & $4,6 a b$ \\
\hline & 6,9 & 58 a & $1.642 \mathrm{a}$ & $0,18 a b$ & $1,83 \mathrm{~cd}$ & $4,4 \mathrm{bc}$ \\
\hline & Com N & $0 \mathrm{e}$ & $0 \mathrm{~cd}$ & $0,00 \mathrm{c}$ & $2,40 a$ & $4,8 a b$ \\
\hline & Sem N & $0 \mathrm{e}$ & $0 \mathrm{~cd}$ & $0,00 \mathrm{c}$ & $1,98 \mathrm{bcd}$ & $3,9 \mathrm{~cd}$ \\
\hline
\end{tabular}

Médias seguidas pela mesma letra, na mesma coluna, não diferem entre si pelo teste de Duncan a 5\% de significância.

Todavia, é interessante observar que a estirpe INPA 03-11B, isolada de Centrosema sp de soloácido da Amazônia e eficiente para Vigna unguiculata (feijão caupi), mas que, até o momento, não havia sido testada quanto à sua eficiência em soja, apresentou uma resposta semel hanteà das estirpes já recomendadas, $\mathrm{Br} 29$ e SEMIA 587.

A atividade da Nase foi maior para as estirpes $\mathrm{Br} 29$ e INPA 03-11B. Para todas as estirpes não houve diferença entre os tratamentos de inoculação com diferentes valores de $\mathrm{pH}$.

Embora exista correlação positiva entre número $\left(r=0,77^{* *}\right)$ e massa de nódulos secos $\left(r=0,76^{* *}\right)$ e a atividade da nitrogenase, nem sempre os tratamentos que promoveram as maiores atividade de Nase apresentaram maior MSPA e MSR.

Os resultados deste experimento demonstraram o efeito da inoculação com as diferentes estirpes nas variáveis analisadas, embora, em geral, nãotenham sido observadas diferenças em função do $\mathrm{pH}$ de cultivo das estirpes inoculadas. É possível que o principal fator responsável pela falta de resposta nos diferentes tratamentos de inoculação seja devido à não-correção da turfa para os valores de $\mathrm{pH}$ correspondentes aos do meio de cultivo. De qual quer forma, os resultados demonstraram que o uso do pH 6,0 no meio de cultivo de rizóbio utilizado para produção do inoculante em turfa não comprometeu a eficiência simbiótica das estirpes de rizóbio.
Sobrevivência das estirpes de Bradyrhizobi um spp cultivadas e inoculadas em turfa com diferentes valores de $\mathbf{p H}$

No quadro 5, encontram-se os valores deUFC das estirpes de Bradyrhizobium cultivadas e inoculadas em turfa com diferentes valores de $\mathrm{pH}$ que sobreviveram após diferentes períodos de armazenamento.

Houve crescimento de todas as estirpes, logo nos primeiros 15 dias de armazenamento, quando, de modo geral, al cançaram máximos números de UFC nos dois valores de $\mathrm{pH}$, permanecendo semel hantes em $\mathrm{pH}$ 6,9 até os 45 dias, exceto para $\mathrm{Br}$ 4406, que apresentou crescimento até os 30 dias. $\mathrm{Em} \mathrm{pH} \mathrm{6,0,} \mathrm{a}$ estirpe $\mathrm{Br} 29$ foi a única que se mantevecom números máximos atéos 60 dias, enquanto Br 4406, SEMIA 587 elNPA 0311B decresceram, respectivamente, a partir de 45, 30 e 30 dias. Segundo Somasegaran et al. (1984), este aumento é um período de maturação também chamado de "cura", que ocorre devido à utilização de nutrientes ainda presentes no meio de cultura. Passado esse período, a população tende a decrescer e começa se estabilizar, dependendo das condições.

Em relação aos valores de $\mathrm{pH}$ de cultivo e de correção da turfa, percebeu-se que os números de UFC iniciais, calculados a partir da relação entre Log de UFC e densidade ótica (Figura 2), não diferiram, exceto para $\mathrm{Br} 4406$ que, ao longo do período de armazenamento, apresentou menores 


\section{Quadro 5. Unidades Formadoras de Colônias (Log UFC, $\mathrm{g}^{-1}$ inoculante) de estirpes de Bradyrhizobium spp, considerando o pH do inoculante turfoso (meio de cultura mais turfa) em cada período de armazenamento}

\begin{tabular}{|c|c|c|c|c|c|c|c|}
\hline \multirow{2}{*}{ Estirpe } & \multirow{2}{*}{ pH } & \multicolumn{6}{|c|}{ Período (dias) } \\
\hline & & $\mathbf{0}$ & 15 & 30 & 45 & 60 & 75 \\
\hline & & & - & $-\log L$ & $g^{-1}-$ & 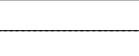 & - \\
\hline \multirow{2}{*}{$\mathrm{Br} 4406$} & 6,0 & $8,06 A^{(1)}$ & $8,78 \mathrm{BC}^{(2)}$ & $9,08 \mathrm{Bb}$ & $9,32 \mathrm{Ba}$ & $8,93 \mathrm{Bbc}$ & $8,48 \mathrm{Ad}$ \\
\hline & 6,9 & 7,81 Be & $9,66 \mathrm{Aab}$ & $9,81 \mathrm{Aa}$ & $9,56 \mathrm{Abc}$ & $9,46 \mathrm{Ac}$ & $8,60 \mathrm{Ad}$ \\
\hline \multirow{2}{*}{ Br 29} & 6,0 & $8,06 \mathrm{Ac}$ & 9,85 $\mathrm{Aa}$ & 9,71 Bab & $9,61 \mathrm{Aab}$ & 9,67 Aab & $9,44 \mathrm{Ab}$ \\
\hline & 6,9 & $8,19 \mathrm{AC}$ & $9,87 \mathrm{Aa}$ & 9,97 Aa & $9,82 \mathrm{Aa}$ & $8,82 \mathrm{Bb}$ & $8,92 \mathrm{Bb}$ \\
\hline \multirow{2}{*}{ SEMIA 587} & 6,0 & 7,95 Ae & 9,83 $\mathrm{Aa}$ & $9,70 \mathrm{Bab}$ & $9,41 \mathrm{BC}$ & $9,53 \mathrm{Abc}$ & $9,20 \mathrm{Ad}$ \\
\hline & 6,9 & $8,01 \mathrm{Ac}$ & 9,99 Aa & $10,06 \mathrm{Aa}$ & 9,96 Aa & $9,14 \mathrm{Bb}$ & $9,07 \mathrm{Ab}$ \\
\hline \multirow{2}{*}{ INPA 03-11B } & 6,0 & 7,95 Ad & $9,86 \mathrm{Aa}$ & $9,73 \mathrm{Aa}$ & $9,46 \mathrm{Bb}$ & $9,22 \mathrm{Abc}$ & $9,15 \mathrm{AC}$ \\
\hline & 6,9 & $8,03 \mathrm{AC}$ & $10,04 \mathrm{Aa}$ & $10,06 \mathrm{Ba}$ & 9,93 Aa & $9,17 \mathrm{Ab}$ & $8,98 \mathrm{Ab}$ \\
\hline
\end{tabular}

(1) Valores de UFC calculados a partir da relação entre o log de UFC a densidade ótica. (2) Médias seguidas pela mesma letra maiúscula, na coluna, e minúscula, na linha, não diferem entre si pelo teste de Duncan a 5\% de significância.

números deUFC em pH 6,0 em relaçãoa pH 6,9 até 60 dias, embora os números de UFC iniciais fossem maiores. Todavia, aos 75 dias, não houve diferença na UFC entreos dois val ores depH para esta estirpe. Um dos destaques dessa estirpe é a produção de exopolissacarídeos sob estresse (Figura 3). Segundo Dilworth et al. (1999), sob condições de acidez, a produção de exopol issacarídeos pode-setornar mais um fator de estresse. Entretanto, considerando que este também pode ser um fator de adaptação à acidez, o investimento em exopol issacarídeos como forma de tolerância a este estresse parece ser o mecanismo que, ao final dos 75 dias, garante números de UFCs semel hantes nos dois valores de $\mathrm{pH}$.

De modo geral, as estirpes mantiveram a tendência de maiores números de UFC em pH 6,9 até 45 dias. Aofinal dos 75 dias não diferiram, exceto para $\mathrm{Br} 29$, que sobreviveu melhor em $\mathrm{pH} 6,0$. Assim, os menores números de UFC em pH 6,0 até os 45 dias de armazenamento podem ser devidos à pré-adaptação ao pH levemente ácido (acid habituation), durante o cultivo em $\mathrm{pH} 6,0$. O efeito da concentração de cál cio varia com o pH, entretanto, aumentando-se a concentração de cál cio, ocorre um aumento em termos de sobrevivência celular (Dilworth et al., 1999). A taxa de crescimento é estimulada pela presença do cál cio, sendo este efeito maior quando as células de rizóbio estavam sob estresse provocado pel a acidez (Howieson et al., 1992; Reeve et al., 1993). Assim, embora a quantidade de cálcio usada para corrigir a turfa para pH 6,9 tenha sido mai or, a concentração de cál cioteve efeito menor sobre pH alcalino e neutro. Ressalta-se que, no final do experimento (75 dias), todas as estirpes apresentaram valores de UFC no inoculante superiores aos atualmente recomendados pela RELARE ( $10^{8} \mathrm{~g}^{-1}$ inoculante).

Atualmente, tanto o $\mathrm{pH}$ da turfa como o do meio de cultivo das estirpes, usados para produção de inoculantes no Brasil eem outros países, são corrigi dos para valor em torno de 6,8. Os resultados dos experimentos demonstraram que o $\mathrm{pH}$ de cultivo e o de correção da turfa influenciaram a sobrevivência de estirpes de Bradyrhizobium e mostraram a possibilidade do uso de inoculantes corrigi dos para valor de pH 6,0, como modo de pré-adaptação das estirpes inoculantes à condição de acidez dos solos tropicais.

\section{CONCLUSÕES}

1. As estirpes de Bradyrhizobium ( $\mathrm{Br} 4406, \mathrm{Br} 29$, SE MIA 587 e INPA403-11B) tiveram um comportamento diferenciado em meio líquido com $\mathrm{pH}$ 5,0,6,0 e 6,9, obtendo mel hor desempenho em $\mathrm{pH} 6,0$, tanto em número de UFC quanto em produção de exopolissacarídeos.

2. A tolerância a pH 6,0 pode estar relacionada com a maior quantidade de exopol issacarídeos.

3. Os valores de pH 5,0, 6,0 e 6,9 utilizados no cultivo derizóbio em inoculanteturfoso não afetaram a eficiência simbiótica das estirpes em soja. 
4. O melhor crescimento das estirpes de Bradyrhizobium em meio de cultivo com pH 6,0 e sua maior sobrevivência em turfa com pH corrigido para 6,0 indicaram como alternativa vantajosa ouso de inoculantes corrigidos para esse valor de $\mathrm{pH}$.

\section{LITE RATURA CITADA}

CAMARGO, O.A.; MONIZ, A.C.; J ORGE, J .A. \& VALADARES, J.M.A.S. Métodos de análise química, mineralógica e física de solos do Instituto Agronômico de Campinas. Campinas, Instituto Agronômico de Campinas, 1986. 94p.

CORREA, O.S. \& BARNEX, A.J. Cellular mechanisms of pH tolerance in Rhizobium loti. World J . Microbiol. Biotechnol., 13:153-157, 1997.

CUNNINGHAM, S.D. \& MUNNS, D.N. Effects of rhizobial extracellular polysaccharide on $\mathrm{pH}$ and aluminum activity. Soil Sci. Soc. Am. J ., 48:1276-1280, 1984b.

CUNNINGHAM, S.D. \& MUNNS, D.N. The correlation between extracellular polysaccharide production and acid tolerance in Rhizobium. Soil Sci. Soc. Am. J ., 48:1273-1276, 1984a.

DILWORTH, M.J. Acetylene reduction by nitrogen-fixing preparations from Clostridium pasteurianum. Biochem. Biophysiol. Acta, 127:285-294, 1966.

DILWORTH, M.J .; RYNNE, F.G.; CASTELLI, VIVAS-MARFISI, A.I. \& GLENN, A.R. Survival and exopolysaccharide production in Sinorhizobium mel iloti WSM 419 are affected by calcium and low pH. Microbiology, 145:1585-1593, 1999.

DOBEREINER, J.\& DUQUE, F.F. Contribuição da pesquisa em fixação biológica de nitrogênio para o desenvol vimento do Brasil. R. Econ. Rural, 18:447-460, 1980.

EMPRESA BRASILEIRA DE PESQUISA AGROPECUÁRIA EMBRAPA. Serviço Nacional de Levantamento e Conservação de Solos. Manual de métodos e análises de solos. Rio de J aneiro, 1979. 79p.

FABER, J.M. \& PAGOTTO, F. The effects of acid shock on the heat resistence of Listeria monocytogenes. Letters Appl. Microbiol., 15:197-201, 1992.

FIGUEIREDO, M.V.B.; STAMFORD, N.P.\& BURITY,H.A. Efeito da temperatura de armazenamento na sobrevivência do Bradyrhizobium sp. em substratos alternativos. R. Bras. Ci. Solo, 15:173-178, 1991.

FOSTER, J.W. \& HALL, H.K. Inducible pH homeostasis and the acid tolerance response of Salmonella typhimurium. J . Bacteriol., 173:129-5135, 1991.

GOODSON, M. \& ROWBURY, R.J . Habituation to normally lethal acidity by prior growth Escherichia coli at a sub lethal acid pH value. Letters Appl. Microbiol., 8:77-79, 1989a.

GOODSON, M. \& ROWBURY, R.J . Resistence of acid-habituation Escherichia coli to organic acids and its medical and applied significance. Letters Appl. Microbiol., 8:211-214, 1989b.

GRAHAM, P.H. Stress tolerance in Rhizobium and Bradyrhizobium, and nodulation under adverse soil conditions. Can. J. Microbiol., 38:475-484, 1991.
GRAHAM, P.H.; VITERI, S.E.; MACKIE, F.; VARGAS, A.T. \& PALACIOS, A. Variation in acid soil toleranceamong strains of Rhizobium phaseoli. Field Crops Res., 5:121-128, 1982.

HARTEL, P.G. \& ALEXANDER, M. Growth and survival of cowpea rhizobia in acid, aluminum-rich soils. Soil Sci. Soc. Am. J ., 47:502-506, 1983.

HOWIESON, J .G.; ROBSON, A. D. \& ABBOTT, L.K. Acid tolerant species of Medicago produce root exudates at low $\mathrm{pH}$ which induce the expression of nodulation genes in Rhizobium meliloti. Aust. J. Plant Physiol., 19:287-296, 1992.

HOWIESON, J.G \& EWING, M.A. Acid tolerance in the Rhizobium meliloti-Medicago Symbiosis. Aust.J . Agric. Res., 37:55-64, 1986.

KEYSER, H.H.\& MUNNS, D.N. Effects of calcium, manganese, and aluminium on growth of rhizobia in acid media. Soil Sci. Soc. Am. J., 43:500-503, 1979a.

KEYSER, H.H. \& MUNNS, D.N. Tolerance of rhizobia to acidity, aluminum, and phosphate. Soil Sci. Soc. Am. J ., 43:519-523, 1979b.

MAGALHÃES, F.M.M. Present state of knowledge on biological nitrogen fixation in Amazonia. In: SYMPOSIUM ON THE HUMID TROPICS, 1., Belém, 1986. Proceedings. Belém, Empresa Brasileira de Pesquisa Agropecuaria, 1986. v.1. p.499-512.

MATSUDA, A. Tolerância "in vitro" e sobrevivência no solo de espécies de rizóbio de leguminosas tropicais a metais pesados. Lavras, UniversidadeFederal de Lavras, 2000. 85p. (Tese de Mestrado)

MILES, A.A. \& MISRA, S.S. The estimations of the bacteriocidal power of the blood. J. Hyg., 38:732-749, 1938.

MOREIRA, F.M.S.; HAUKKA, K. \& YOUNG, J .P.W. Biodiversity of rhizobia isolated from a wide range of forest legumes in Brazil. Molec. Ecol., 7:889-995, 1998.

MOROTE, C.G.B.; VIDOR, C.; MENDES, N.G. \& PEREIRA, J.S. Melhoria da nodulação da soja pela cobertura do solo e inoculação com Bradyrhizobium japonicum. R. Bras. Ci. Solo, 14:143-150, 1990.

NEVES, M.C.P.; RAMOS, M.L.G.; MARTINAZZO, A.R.; BOTELHO, G.R. \& DÖBEREINER, J . Adaptation of more efficient soybean and cowpea rhizobia to replace established populations. In: MULONGOV, K.; GUEYE, M.\& SPENCER, D.S.C., eds. Biological nitrogen fixation and sustainability of tropical agriculture. Chichester, Wiley-Sayce, 1992. p.219233.

O'HARA, G.W. \& GLENN, A.R. The adaptive acid tolerance response in root nodule bacteria and Escherichia coli. Arch. Microbiol., 161:286-292, 1994.

O'HARA, G.W.; GOSS, T.J. DILWORTH, M.J . \& GLENN, A.R. Maintenance of intracellular $\mathrm{pH}$ and acid tolerance in Rhizobium meliloti. Appl. Environ. Microbiol., 55:18701876, 1989.

OLIVEIRA, J.C.; RAMOS, M.L.G. \& DUQUE, F.F. Inoculação da soja, em solo de cerrado no primeiro ano de cultivo. R. Bras. Ci. Solo, 15:273-276, 1991. 
PERES, J.R.R.; MENDES, I.C.; SUHET, A.R. \& VARGAS, M.A.T. Eficiência e competitividade de estirpes de rizóbio para soja em solos de cerrado. R. Bras. Ci. Solo, 17:357-363, 1993.

PERES, J .R.R. \& VIDOR, C. Relação entre concentração de células no inoculante e competição por sítios de infecção nodular entre estirpes de Rhizobium japonicum em soja. R. Bras. Ci. Solo, 4:139-143, 1980

REEVE, W.G.; DILWORTH, M.J .; TIWARI, R.P. \& GLENN, A.R. Regulation of exopolysaccharide production in Rhizobium leguminosarum biovar viciae WSM 710 involves exoR. Microbiology, 143:1951-1958, 1997.

REEVE, W.G.; TIWARI, R.P.; DILWORTH, M.J . \& GLENN, A.R. Calcium affects the growth and survival of Rhizobium meliloti. Soil Biol. Biochem., 25:581-586, 1993.

RIBEIRO J r., W.Q.; FRANCO, A.A. \& LOPES, E.S. Eficiência e competitividade de estirpes de Bradyrhizobium spp., para Enterol obi um contorti siliquum, em latossolo ácido. R. Bras. Ci. Solo, 10:219-225, 1986.

RIBEIRO J r., W.Q.; LOPES, E.S. \& FRANCO, A.A. Eficiência de estirpes de Bradyrhizobium spp., para quatro leguminosas arbóreas e competividade das estirpes em Albizia lebbek em latossolo ácido. R. Bras. Ci. Solo, 11:275-282, 1987.

RICHARDSON, A.E. \& SIMPSON, R.J. Acid-tolerance and symbiotic effectiveness of Rhizobium trifolii associated with a Trifolium subterraneum L. basead pasture growing in na acid soil. Soil Biol. Biochem., 21:87-95, 1989.
SOMASEGARAN, P.; REYES, V,G. \& HOBEN, H.J . The influence of high temperatures on the growth and survival of Rhizobium spp, in peat inoculants during preparation, storage, and distribution. Can. J . Microbiol., 29:23-30, 1984.

SPARROW, S.D. \& HAM, G.E. Survival of Rhizobium phaseoli in six carrier materials. Agron. J ., 75:181-184, 1983.

THORNTON, F. C. \& DAVEY, C.B. Acid tolerance of Rhizobium in culture media. Soil Sci. Soc. Am. J ., 47:496-501, 1983.

TRANNIN, I.; MOREIRA, F.M.S.; SIQUEIRA, J .O. \& LIMA, A.S. Tolerância de estirpes e isolados de Bradyrhizobium e Azorhizobium a zinco, cádmio e cobre "in vitro". R. Bras. Ci. Solo, 25:305-316, 2001.

VARGAS, M.A.T.; PERES, J.R.R. \& SUHET, A.R. Adubação nitrogenada, inoculação e épocas de calagem para a soja em um sol o sob cerrado. Pesq. Agropec. Bras., 17:1127-1132, 1982.

VARGAS, M.A.T. \& SUHET, A.R. Efeitos da inoculação e deficiência hídrica no desenvolvimento da soja em um solo de cerrado. R. Bras. Ci. Solo, 4:17-21, 1980.

VETTORI, L. Métodos de análise de solo. Rio de J aneiro, Ministério da Agricultura, 1969. 24p. (Boletim técnico, 7)

VIDOR, C.; KOLLING, J .; FREIRE, J,R.J .; SCHOLLES, D.; BROSE, E. \& PEDROSO, M.H.T. Fixação biológica de nitrogênio pela simbiose entre Rhizobium e leguminosas. Porto Alegre, IPAGRO, 1983. p.51 (Boletim técnico,1)

VINCENT, J.M. A manual for the practical study of the root nodule bacteria. London, J BP, 1970. 164p. (Handl book, 15) 
